\title{
ENSINO MÉDIO COM INTERMEDIAÇ̃̃o TECNOLÓGICA (EMITec): ANÁLISE DA PROPOSTA CURRICULAR ${ }^{1}$
}

\author{
ENSEÑANZA MÉDIA COM INTERMEDIACIÓN TECNOLÓGICA (EMITec): \\ ANALISIS DE LA PROPUESTA CURRICULAR
}

\author{
HIGH SCHOOL WITH TECHNOLOGICAL INTERMEDIATION (EMITec): ANALYSIS \\ OF THE CURRICULUM PROPOSAL
}

\author{
Eudite Fernandes CARNEIRO ${ }^{2}$ \\ Benedito Gonçalves EUGENIO ${ }^{3}$
}

RESUMO: Este artigo apresenta os resultados de uma pesquisa que investigou a política curricular para o Ensino Médio no Estado da Bahia. O foco do texto são os indícios do processo de recontextualização discursiva, presentes na política curricular da proposta do Ensino Médio com Intermediação Tecnológica (EMITec). Apresentamos um panorama geral do programa, destacando a organização curricular e evidenciamos algumas discussões sobre as influências presentes na produção do discurso do EMITec. Para isso, transitamos por alguns conceitos fundamentais da teoria do dispositivo pedagógico de Basil Bernstein (1996; 1998), especialmente sua produção sobre a recontextualização pedagógica dos discursos. Com base nos apontamentos realizados, podemos inferir que os princípios recontextualizadores imprimidos ao EMITec produzem novos e diferentes discursos.

PALAVRAS-CHAVE: Política curricular. EMITec. Recontextualização. Currículo.

RESUMEN: Este artículo presenta los resultados de una investigación sobre la política curricular para la escuela secundaria en el estado de Bahía. El enfoque del texto es la evidencia del proceso de recontextualización discursiva presente en la política curricular de la propuesta de la Escuela Secundaria con Intermediación Tecnológica (EMITec). Presentamos una visión general del programa, destacando la organización curricular y destacamos algunas discusiones sobre las influencias presentes en la producción del discurso de EMITec. Para ello, revisamos algunos conceptos fundamentales de la teoría del dispositivo pedagógico de Basil Bernstein (1996, 1998), especialmente su producción sobre la recontextualización pedagógica de los discursos. Con base en las notas hechas, podemos inferir que los principios de recontextualización impresos en EMITec producen discursos nuevos y diferentes.

PALABRAS CLAVE: Política curricular. EMITec. Recontextualización. Currículum.

\footnotetext{
${ }^{1}$ Este artigo é um recorte da dissertação de mestrado defendida em 2019.

${ }^{2}$ Universidade Estadual do Sudoeste da Bahia (UESB), Vitória da Conquista - BA - Brasil. Mestre em Ensino. Email: eudite.carneiro@enova.educacao.ba.gov.br

${ }^{3}$ Universidade Estadual do Sudoeste da Bahia (UESB), Vitória da Conquista - BA - Brasil. Prof. Titular do Departamento de Filosofia e Ciências Humanas (DFCH) e do Programa de Pós-graduação em Ensino (PPGEn). ORCID: https://orcid.org/0000-0002-5781-764X. E-mail: dodoeugenio@gmail.com
} 
ABSTRACT: This article presents the results of a research that investigated the curriculum policy for high school in the State of Bahia. The focus of the text is the evidence of the recontextualization process present in the curricular policy of the proposal of High School with Technological Intermediation (EMITec). We present an overview of the program, highlighting the curricular organization and emphasize some discussions about the influences present in the production of EMITec's discourse. For this, we go through some fundamental concepts of the theory of the pedagogical device of Basil Bernstein (1996; 1998), especially his production on the pedagogical recontextualization of the speeches. Based on the notes made, we can infer that the recontextualizing principles printed to EMITec produce new and different discourses.

KEYWORDS: Curriculum policy. EMITec. Recontextualization. Curriculum.

\section{Introdução}

A teoria do dispositivo pedagógico constitui um conjunto de conceitos que possibilitam a investigação do discurso pedagógico, descrevendo os fundamentos relativos à produção, reprodução, aquisição e mudanças pelas quais o discurso pedagógico passa durante essa trajetória (BERNSTEIN, 1996). As regras recontextualizadoras, destacadas neste estudo, reguladas pelas regras distributivas e regulando as regras de avaliação, agem diretamente no processo de formação do discurso pedagógico (BERNSTEIN, 1998).

Os construtos teóricos de Basil Bernstein constituem um conjunto de conceitos e princípios densos, que para serem mais bem compreendidos, exigem capacidade de abstração, considerada como complexa por alguns autores. Entretanto, seus conceitos se adequam perfeitamente a nossa investigação, principalmente em função da linguagem de descrição, que utiliza a teoria para iluminar a empiria, em uma relação cíclica entre os conceitos da teoria e os dados empíricos analisados.

Tendo como foco o Ensino Médio com Intermediação Tecnológica - EMITec, política curricular baiana proposta para o Ensino Médio rural e para localidades com número insuficiente de profissionais com formação específica em determinadas áreas de conhecimento, operamos com o conceito de recontextualização, nos contextos propostos por Bernstein (1996; 1998), a saber Campo de Recontextualização Oficial (CRO) e Campo de Recontextualização Pedagógica (CRP), em que essa política curricular é colocada em prática. Em nosso estudo, o processo de recontextualização refere-se à transformação pela qual passam os textos elaborados em função desta política curricular, desde o momento da sua produção até alcançar o ambiente da prática pedagógica, nas telessalas do EMITec, onde constituem o próprio discurso pedagógico.

Para Bernstein (1996; 2003), existem dois campos recontextualizadores (que aqui não se referem a espaço geográfico, mas sim, a diferentes relações entre pessoas e instituições): o 
CRO e o CRP. O primeiro é o espaço de produção dos discursos pedagógicos oficiais, "regulado diretamente pelo Estado, politicamente através do legislativo, administrativamente através da administração pública". As orientações curriculares regulamentadas no CRO sofrem influência direta do campo internacional e depois são combinadas aos diversificados discursos que circulam no campo nacional. Podemos dizer que o CRO é o primeiro nível de recontextualização dos discursos oficiais (BERNSTEIN, 1996, p. 276).

Já o CRP é um campo não oficial, "constituído por pedagogos em escolas, faculdades e setores de educação de universidades com suas pesquisas, periódicos e jornais especializados, fundações privadas de pesquisa" (MAINARDES; STREMEL, 2010, p. 13). Neste campo, as teorias educacionais, sujeitas a mecanismos de recontextualização, orientam a prática pedagógica. As condutas pessoais e posicionamentos assumidos neste contexto e introduzem diferentes significados aos discursos.

Este artigo apresenta os resultados de uma pesquisa qualitativa do tipo estudo de caso, cujo objetivo foi compreender indícios do processo de recontextualização do discurso presentes na política curricular proposta para o Ensino Médio com Intermediação Tecnológica (EMITec) da Secretaria Estadual de Educação da Bahia. A base teórica da investigação foi Basil Bernstein (1996; 1998) e os dados foram construídos por meio da análise de documentos e entrevistas.

\section{Um panorama geral do EMITec no Estado da Bahia}

O EMITec foi implantado na Bahia por meio da Portaria $n^{\circ} 424$, de 21 de janeiro de 2011 (BAHIA, 2011), em substituição ao Ensino Médio no Campo com Intermediação Tecnológica (EmC@mpo). Ao contrário do EmC@mpo, o EMITec ampliou o público-alvo a ser atendido, passando também a incluir estudantes da zona urbana. De acordo com Santos (2015, p. 15), o EMITec visa suprir três aspectos desafiadores da educação na Bahia. O primeiro se refere à grande extensão territorial baiana, abarcando 417 municípios. O segundo está relacionado à necessidade de suprir a "carência de docentes habilitados em diferentes componentes curriculares, sobretudo em localidades longínquas". E, o terceiro aspecto é definido como a necessidade de aplacar as desigualdades socioculturais por meio da socialização e da troca de saberes locais e globais (CARNEIRO, 2019, p. 83-84).

É importante destacar que mesmo fazendo uso de alguns fundamentos da Educação a Distância (EaD), o EMITec não se insere em tal modalidade de ensino, visto que "as aulas são ao vivo, presenciais, e diárias, com 200 dias letivos, daí a classificação como Ensino Médio regular, presencial com intermediação tecnológica e não Educação a Distância (EaD)" 
(OLIVEIRA et al., 2015, p. 37). De acordo com Santos (2015, p. 15), “O EMITec é considerado atualmente como uma modalidade educacional, e se caracteriza por realizar aulas ao vivo e interativas, com o uso de solução de comunicação via satélite e com o software IPTV ${ }^{4}$ ”.

Ao justificar a criação do EMITec na Bahia, em entrevista realizada no dia 05 de setembro de 2018, a coordenadora executiva do programa esclarece que, além da grande extensão territorial, a Bahia possui municípios distantes dos centros urbanos, o que conduz à evasão de alunos, dada a distância dessas localidades até a escola mais próxima. Krawczyk e Silva (2017, p. 14) afirmam que a despeito do avanço registrado no Brasil nos últimos 20 anos, no que se refere aos indicadores de acesso e permanência na escola, "a garantia do direito ao Ensino Médio segue como uma questão não resolvida pelas políticas públicas educacionais, persistindo o desafio da sua universalização, com qualidade social”. Essa preocupação também é relatada pela coordenadora executiva do EMITec quando diz:

[...] o secretário já vinha detectando a necessidade de melhorar o Ideb da rede estadual e ao mesmo tempo melhorar a qualidade de vida dessa população da zona rural, onde a distância das localidades que moravam, para escola no centro urbano, era muito grande e isso estava promovendo uma evasão. [...] Então, foi nesse sentido que veio a demanda, de fazer uso de alguns princípios da educação a distância, dentro da rede estadual (Entrevista, coordenadora executiva do EMITec, 2018).

Preconizando constituir-se como uma tecnologia social inovadora na educação básica, alternativa pedagógica inclusiva que faz uso da intermediação tecnológica, o EMITec alcança, de acordo com os dados de 2018, extraídos na secretaria no Secretaria do Centro Estadual de Referência do Ensino Médio com Intermediação Tecnológica - CEMITEC em 2019, 155 municípios baianos (referência). Os 155 municípios, englobaram, em 2018, 355 localidades, em um total de 1.057 turmas e 19.730 alunos matriculados.

Segundo Oliveira et al. (2015, p. 55):

a cada teleaulas ${ }^{6}$ iniciada, uma nova história se escreve: a do professor que a leciona, a do aluno que a assiste e participa, a do mediador que coordena a telessala, presencialmente, na localidade e a da equipe de estúdio, que acompanha o desempenho do professor [...], assim como também acompanha o trabalho do mediador que deve administrar coerentemente o chat $^{7} \mathrm{e}$ organizar a participação dos alunos [...].

${ }^{4}$ IPTV (Internet Protocol Television) ou TVIP (Televisão por IP) é uma tecnologia que permite a transmissão de sinais de TV via Internet, mas diferentemente dos sistemas tradicionais televisivos, o IPTV oferece a capacidade de transmitir a mídia de origem continuamente.

${ }^{5}$ Secretário de Educação do Estado da Bahia (SEC-BA).

${ }^{6}$ No EMITec, as teleaulas são aulas ministradas à distância, através do uso de tecnologias de comunicação até alcançar as telessalas, ou seja, salas de aula onde os discentes do EMITec assistem as teleaulas em tempo real.

${ }^{7}$ Chat aqui designa conversação em tempo real por meio de páginas $W e b$. 
Para gerir o programa, no Centro Estadual de Referência do Ensino Médio com Intermediação Tecnológica - (CEMITEC), com sede em Salvador, encontra-se a direção geral do projeto. O CEMITEC é uma escola de porte especial que concentra os membros da coordenação executiva e pedagógica do programa, coordenadores, docentes de todas as áreas e equipe técnica especializada. Juntos, são responsáveis pelo planejamento, execução e transmissão das teleaulas para todas as localidades de abrangência do programa na Bahia.

Para Bernstein, as agências e agentes são responsáveis por significativas transformações no conhecimento construído por meio de processos discursivos. A escola é uma agência recontextualizadora de controle simbólico. Os discursos, materializados em textos, em palavras, em vídeos, em música e em diversas outras ações, transitam por diversos contextos, onde são (re)interpretados, (re)significados e, portanto, (re)contextualizados. No CEMITEC ocorre o primeiro nível da recontextualização, por meio da ação dos agentes recontextualizadores, constituídos por toda a equipe envolvida no processo de elaboração e transmissão das teleaulas (BERNSTEIN, 1996).

Ainda que seja uma escola, o CEMITEC não conta com salas de aula, no modelo convencional, em que professores e alunos interagem em um mesmo espaço, contando com a presença física de ambos. As aulas são gravadas pelos professores com apoio de toda a equipe que constitui o programa, nos três estúdios instalados no CEMITEC e transmitidas para as telessalas espalhadas pelo Estado da Bahia.

Dessa forma, essa solução tecnológica, permite que, em diferentes espaços, estudantes e professores interajam em tempo real, com aulas ao vivo diariamente, construindo conhecimentos e elucidando dúvidas em cada um dos componentes curriculares que compõem o currículo do ensino médio (FILHO; SANTOS, 2015, p. 21).

Na dinâmica exposta, é possível percebermos a existência do movimento de deslocação e relocação do discurso pedagógico, quando o discurso original (re)construído pelos docentes e coordenadores do EMITec, durante a preparação das aulas no CEMITEC, e transmitidos por meio dos estúdios de gravação, passa por uma transformação, de uma prática concreta para uma prática virtual. "Trata-se de um princípio recontextualizador que, seletivamente, apropria, reloca, refocaliza e relaciona outros discursos, para constituir sua própria ordem e seus próprios ordenamentos" (BERNSTEIN, 1996, p. 259).

Em virtude da distância entre o CEMITEC, com sede em Salvador, e os municípios atendidos pelo EMITec, pulverizados por todo o território baiano, para acompanhar e prestar suporte, tanto administrativo quanto pedagógico às escolas de vinculação. Em 2013 foi fundado 
um órgão denominado Centro Regional de Ensino Médio com Intermediação Tecnológica (CEMIT), por meio da Portaria n ${ }^{\circ}$ 84/2013, publicada no Diário Oficial de 8 de janeiro de 2013 (OLIVEIRA et al., 2015).

A escola de vinculação é uma escola estadual com responsabilidade de gerir o funcionamento do programa nas telessalas que, normalmente, estão instaladas nas escolas anexas, ou seja, escolas municipais, que mediante acordo com o Estado da Bahia, cedem algumas salas de aula para a realização das teleaulas do EMITec. Em entrevista com a coordenadora executiva do programa, ela nos informou que anteriormente, por meio de um convênio de parceria realizado entre Estado/município, o município se responsabilizava pelo pagamento do mediador. Todavia, ao longo do tempo, o próprio Estado assumiu essa remuneração, uma vez que o Ensino Médio não é uma responsabilidade do município, mas sim, do próprio Estado. Com efeito, segundo Bernstein (1996, p. 92), o trajeto realizado pelo conhecimento, que "sofre uma transformação ou reposicionamento adicional na medida em que se torna ativo no processo pedagógico" é dinâmico, sujeito a transformações, mutações e a diferentes pressões advindas de diversos campos.

Em 2019, o CEMIT encontra-se implantado e em funcionamento em dez municípios baianos, sendo que dois são no mesmo município, Bom Jesus da Lapa, devido à extensão e quantidade de alunos, perfazendo um total de onze CEMIT. Segundo Oliveira et al. (2015, p. 37), cada CEMIT tem a função de "dispor de um mecanismo de acompanhamento pedagógico e administrativo local, que se faça presente de forma célere, dado as distâncias das localidades em relação às instalações da Coordenação geral" do programa. Na ausência do CEMIT, o acompanhamento às escolas de vinculação é realizado por um dos Núcleos Territoriais de Educação (NTE).

$\mathrm{Na}$ implantação do CEMIT, vemos presentes traços relevantes do sentido atribuído às relações de poder e controle que determinam a forma e o posicionamento do discurso curricular, cerceado pelo controle simbólico atribuído às escolas. O CEMIT, como agente de controle simbólico, por sua vez, submetido à direção geral do CEMITEC, regulador dos discursos a serem transmitidos ao público adquirente, discentes do EMITec, que receberão e responderão às mensagens dos discursos (BERNSTEIN, 1996).

O EMITec segue como modelo o currículo do Ensino Médio presencial. Todavia, as entrevistas realizadas com os docentes deixam claro a necessidade de uma adequação dos conteúdos. Ao ser perguntado acerca dos materiais curriculares a serem consultados para a elaboração de aulas, o professor de História do EMITec [2019], relatou que, em sua prática, além da utilização do livro didático, que "são sugestões do EMITec pra que o Estado adote 
com essas comunidades" também utiliza "material de apoio [...] com textos retirados de trabalhos acadêmicos [...] e de sites [...] que tenham uma credibilidade”. Na sua fala, enfatiza: "então a gente faz esse recorte/cola e oferece esse material de apoio". A professora de Filosofia, relatou que, além da utilização dos livros didáticos de filosofia, também trabalha com "material de poio do próprio EMITec, que já foi confeccionado antes". A professora de Geografia reforça: "não tem algo assim engessado, é muito aberto a vídeos, documentários, artigos, entrevistas, então, assim, é uma infinidade de fontes. Não tem algo engessado".

De acordo com Mainardes e Stremel (2010, p. 42), "Bernstein distingue dois tipos de conhecimento: o impensável (controlado essencialmente pelos que produzem os novos discursos) e o pensável (controlado essencialmente pelos que atuam no contexto da reprodução do discurso)". Com base na discussão de Bernstein (1996, p. 255): “As regras distributivas fundamentais marcam e especializam o pensável e o impensável e suas consequentes práticas para os diferentes grupos, através da mediação de práticas pedagógicas diferentemente especializadas". Concluímos que para efeitos desta pesquisa, podemos considerar que os docentes do EMITec, juntamente com os coordenadores pedagógicos, são os responsáveis pela reprodução do discurso, decidindo o conhecimento pensável.

Todo o planejamento das aulas, incluindo a preparação das atividades, acontece na sala de professores, onde as teleaulas são criadas e os ajustes são realizados. De acordo com Filho e Santos (2015, p. 27), essa preparação exige a participação de coordenadores pedagógicos em conjunto com a equipe de professores, que, juntos, realizam pesquisas, selecionam e produzem "recursos audiovisuais para uso durante as teleaulas, e posterior construção da sequência didática destas aulas". Segundo os autores, o planejamento de uma teleaula deve seguir a um roteiro pré-definido, contendo, além de "um recurso audiovisual, uma questão contextualizada no modelo das questões do Exame Nacional do Ensino Médio (ENEM), retomada da aula anterior como momento de revisão e uma atividade de produção para o aluno".

O sistema de avaliação do EMITec conta com uma variedade de estratégias que são desenvolvidas pelos docentes em conjunto com a coordenação pedagógica e com setor de avaliação. Os principais instrumentos avaliativos utilizados são: “Atividade Dirigida (AD); avaliação Presencial por Área (APA); Avaliação Qualitativa (AQ); Momento de Retomada dos Conteúdos (MRC); e a Prova Final (PF)" (SANTOS et al., 2012, p. 4).

A $\mathrm{AD}$, planejada pelo docente especialista e realizada sob o monitoramento do mediador, é elaborada previamente, de forma detalhada em formulário, com base no calendário letivo, e combina ações de natureza teórica e prática, quem podem ser materializadas em 
"gincana do conhecimento, feira do conhecimento, entre outras atividades", que podem ser realizadas individualmente, em dupla ou em grupo.

De preenchimento obrigatoriamente individual, a APA também é elaborada pelo docente especialista, com "10 questões objetivas e 02 questões discursivas interdisciplinares, construídas em formulário padrão" que deve ser respondido pelo discente, sem nenhum tipo de consulta. Na AQ, o mediador deve avaliar nos alunos, questões relacionadas a: "assiduidade, pontualidade, interação, capacidade comunicativa, realização e entrega das atividades nos prazos estabelecidos pela Equipe Pedagógica do programa”.

A MRC, com características de recuperação paralela, "consiste na revisão ou retomada dos principais conteúdos do semestre" e, por último, a PF, composta por 20 questões objetivas e voltada para os discentes que "não tenham conseguido se apropriar dos conteúdos prioritários revisados e consequentemente a aprovação na disciplina" (SANTOS et al., 2012, p. 5-7).

As ações de acompanhamento e orientação desses instrumentos avaliativos passam pelo crivo do setor de avaliação, que realiza uma análise dos instrumentos elaborados, com vistas à sua adequação "aos objetivos previamente definidos para cada disciplina, bem como, aos interesses e necessidades das localidades assistidas pelo programa" (SANTOS et al., 2012, p. 4-7).

Para Bernstein, a avaliação é uma forma de controle social. Dessa forma, ele defende que o discurso pedagógico seja analisado dentro de uma ótica das relações entre dominantes/dominados. Pelas características que apresenta, o sistema de avaliação do CRO do EMITec é bem definido, com critérios de avaliação explícitos, exibindo características de forte classificação e forte enquadramento, que, na visão do autor, constituem um sistema mais barato do que os modelos que apresentam a classificação e o enquadramento mais fracos e são típicos de uma pedagogia visível (BERNSTEIN, 1996).

Após efetivação de todo o trabalho pedagógico de programação e delineamento das aulas, o conjunto da obra é direcionado ao setor do estúdio, subdividida em outros grupos de trabalho: coordenação tecnológica, sala de controle e estúdio e sala de edição. O trabalho da equipe de estúdio viabiliza a comunicação, entre os docentes do EMITEc e seus discentes, por meio de um arsenal de instrumentos tecnológicos.

De acordo com Oliveira et al. (2015, p. 49), os membros desse setor "buscam direcionar a equipe docente no sentido de se obter uma formação habilidosa e competente do docente que atua diretamente na apresentação das teleaulas". Na sala direcionada à coordenação tecnológica é realizada toda a logística de postagem das aulas. Nela é dispensada atenção especial à qualidade audiovisual e à performance do professor durante as apresentações. 
Na sequência, temos as três salas de estúdios, uma para cada ano do Ensino médio $\left(1^{\circ}\right.$, $2^{\circ}$ e $3^{\circ}$ anos). Em cada sala, controle e estúdio dividem o mesmo espaço, separados apenas por um vidro que isola o espaço onde as teleaulas são gravadas, da parte onde opera a equipe de controle. Na sala de controle, dividem o espaço o diretor de TV e o moderador de IPTV, enquanto dentro do estúdio se posicionam o docente videoconferencista, o docente assistente e o cinegrafista.

O docente videoconferencista é responsável direto pela "explanação do tema da aula" (SANTOS, 2015) e pela interação com os discentes, na medida em que recebe informações da equipe de produção e do docente assistente, que se posiciona ao seu lado no momento de transmissão das teleaulas. Ao docente assistente é delegada a função de interagir com os discentes via chat, por meio de encaminhamentos realizados pelo mediador em atendimento às dúvidas dos discentes, ao passo em que transmite as informações que recebe ao docente videoconferencista. Já a equipe de estúdio fica incumbida de promover a interação dos docentes especialistas com os recursos tecnológicos diversos utilizados para a gravação e transmissão das teleaulas on-line.

Dessa forma, de um dos três estúdios instalados no CEMITEC, um para cada ano do Ensino Médio, parte o sinal, constituído por uma rede de serviços de comunicação multimídia, integrando dados, voz e imagem (videostreaming ${ }^{8}$ ). Passa por uma central, com sede em São Paulo, que retransmite o sinal via satélite, até alcançar as telessalas onde se encontram os alunos e mediadores que integram o EMITec (SANTOS, 2015). Essa plataforma de comunicação constitui uma rede tecnológica que conecta os sujeitos envolvidos de maneira síncrona e presencial, fato que justifica a não inclusão do EMITec na modalidade EaD e a sua caracterização, conforme aponta Santos (2015), como modalidade educacional.

Em outros momentos, as teleaulas serão editadas e convertidas em videoaulas pela equipe responsável pela edição, e ficarão disponíveis e organizadas por disciplina, ano e unidade letiva no Ambiente Educacional Web (AEW) da Plataforma Anísio Teixeira9. Informações colhidas na Plataforma Anísio Teixeira dão conta que o canal do EMITec, no Ambiente Educacional Web, é uma maneira de divulgar e proporcionar acesso aos conteúdos do Ensino Médio considerados prioritários. No ambiente, são disponibilizadas as últimas videoaulas, editadas, para o público interessado, indo além dos estudantes matriculados.

\footnotetext{
8 Streaming ou videostreaming ao vivo é uma tecnologia que, através da Internet, possibilita o envio de informações multimídia para dispositivos sem comprometer sua conexão com a Internet ou exigir um tempo de espera para download e acesso ao conteúdo.

9 Plataforma Anísio Teixeira é um site da Secretaria de Educação do Estado da Bahia. Disponível em: http://pat.educacao.ba.gov.br/emitec. Acesso em: 10 out. 2019.
} 
Durante a transmissão das aulas ao vivo, desenha-se outro cenário, o das telessalas. Nelas, o mediador tem o papel de fazer o acompanhamento constante das teleaulas ministradas on-line para seu público-alvo, constituído, principalmente, por discentes da zona rural. Cada uma das telessalas conta com a supervisão de um mediador, também chamado de tutor, que conduz as atividades e controla a frequência dos discentes. Para que as teleaulas aconteçam, as telessalas integrantes do programa

devem ser equipadas com Antena VSAT bidirecional, roteador-receptor de satélite, cabeamento estruturado (LAN), microcomputador, webcam com microfone embutido, TV LCD 40 polegadas, no mínimo ou datashow, impressora a laser, no-break e acesso à Internet em banda larga via satélite (FILHO; SANTOS, 2015, p. 24).

Esses recursos tecnológicos garantem que o sinal chegue até as regiões mais distantes. Todavia, observamos que a utilização de todo esse aparato tecnológico não pressupõe, conforme preconiza o programa, a inclusão digital dos mediadores e discentes da zona rural baiana. Apesar das telessalas estarem munidas de, no mínimo, um computador, ele, comumente, não é manuseado pelos discentes, ficando restrito apenas ao mediador, que, pontualmente, encaminha as dúvidas por meio dos chats. Dessa forma, utilizando o argumento de Bernstein (2001, p. 16), refletimos que “Compreender a Tecnologia de Informação é bem diferente de ser por ela programado, assumindo-a como fonte de um novo potencial intelectual capaz de libertar aquele que o adquire de limitações sociais e intelectuais características dos velhos conhecimentos".

Fica perceptível, durante a descrição da estrutura organizacional do EMITec, que o programa faz uso de um arsenal de equipamentos tecnológicos como alternativa pedagógica para transmissão das teleaulas. Para isso, conta com a participação de profissionais e técnicos responsáveis por setores tecnológicos, metodológicos e pedagógicos.

\section{Estrutura e organização curricular do EMITec nos documentos Oficiais}

O Discurso Pedagógico Oficial é definido por Bernstein $(1996 ; 1998)$ como um texto produzido para determinado documento escolar, no Campo de Recontextualização Oficial CRO, em decorrência das várias influências advindas dos campos do Estado, do controle simbólico, da economia e do campo internacional, sob os quais, está sujeito a transformações. A exemplo disso, Mainardes (2006, p. 51) afirma que "O discurso em formação algumas vezes recebe apoio e outras vezes é desafiado por princípios e argumentos mais amplos que estão 
exercendo influência nas arenas públicas de ação, particularmente pelos meios de comunicação social".

É nesse campo recontextualizador, sujeito a uma variedade de intenções e disputas, que as políticas educacionais são mobilizadas. Compreender o Discurso Pedagógico Oficial - DPO e as motivações que levaram à elaboração da política para o EMITec, justificam uma das propostas deste estudo, que consiste em analisar os documentos oficiais relacionados ao ato de criação e implantação do EMITec, contextualizando historicamente o processo de implementação do programa na Bahia. Com foco no macro e no microcontexto (textos estruturantes do EMITec sob influência dos documentos nacionais), levamos em conta as relações de poder exercidas por grupos diversos, considerando a "variedade de intenções e disputas que influenciam o processo político", no contexto da influência do ciclo de políticas, proposto por Ball (MAINARDES, 2006, p. 49).

Como já mencionado, o Programa Ensino Médio com Intermediação Tecnológica foi implantado nas unidades escolares da rede pública estadual baiana por meio da Portaria $\mathrm{n}^{\circ} 424$, de 21 de janeiro de 2011 (BAHIA, 2011). Convém aqui levar em consideração o cenário político sob o qual o EMITec emerge, marcado por um período de reformas curriculares para o Ensino Médio, que teve início no governo de Fernando Henrique Cardoso (1995) e perdurou até o governo de Dilma Rousseff (2016), conduzindo um discurso imbuído de ampliar o atendimento às camadas excluídas do acesso aos bens sociais e aos seus direitos.

Essa situação é perceptível na fala da coordenadora executiva do EMITec, ao dizer que a necessidade de melhorar o IDEB da rede estadual baiana "e ao mesmo tempo melhorar a qualidade de vida dessa população da zona rural", motivou a criação do programa EMITec. E reforça a fala anterior dizendo que "a demanda foi em cima da necessidade de resolver um problema social no estado da Bahia, que era a educação na zona rural".

A preocupação demonstrada com o IDEB, segundo a lógica de Ball (2010, p. 487), é percebida na busca por metas, cuja melhoria está atrelada à performatividade. "O indivíduo autogerenciado e a organização autônoma são produzidos dentro dos interstícios da performatividade através de auditorias, inspeções, avaliações, autorrevisões, garantia de qualidade, avaliações de pesquisa, indicadores de resultado etc.”. Segundo Val (2017, p. 17 apud SHIROMA et al., 2017 p. 17), avaliações desse tipo "constituem instrumentos de dominação e reprodução do sistema capitalista que põem no ranking pessoas, instituições e países".

Constatamos que o principal documento orientador do EMITec, portanto DPO, é o Projeto Político Pedagógico do Ensino Médio com Intermediação Tecnológica. Destarte, nossa 
análise está centrada no texto do PPP, que integra as políticas oficiais, definindo os princípios e estratégias para o redesenho curricular do programa, bem como na relação de tal documento com o contexto da influência em nível nacional e com os pressupostos teóricos que dialogam com a nossa pesquisa. Nossa intenção é caracterizar a mensagem veiculada pelo EMITec por meio do texto produzido pelo DPO, caracterizado por Bernstein, complementados pelos fundamentos da abordagem do ciclo de políticas, proposto por Ball, que contempla três principais contextos: de influência, de produção de texto e da prática (BERNSTEIN, 1996; 1998; BALL, 2014; BALL; MAGUIRE; BRAUN, 2016; MAINARDES, 2006).

O EMITec, enquanto programa educacional, pertencente a uma política formulada para um contexto específico, que está sujeito a debates, disputas e influências, em determinado tempo e espaço, estando assim inserido em uma realidade global. Nesse sentido, conforme Neves et al. (2000, p. 213), representa "os princípios dominantes de uma sociedade, que são gerados no Campo do Estado sob a influência do Campo Internacional e dos campos da produção (recursos físicos) e do controlo simbólico (recursos discursivos)", o que nos faz lembrar de Ball (2014, p. 222) quando diz: “[...] na interface entre a política educacional e o neoliberalismo, o dinheiro está em toda a parte. [...] a própria política é agora comprada e vendida, é mercadoria e oportunidade de lucro, há um mercado global crescente de ideias de políticas".

De acordo com o PPP do EMITec, o programa está em consonância com as normas dos seguintes documentos: "Diretrizes Curriculares Nacionais para o Ensino Médio - DCNEM, Parâmetros Curriculares Nacionais para o Ensino Médio - PCNEM, Parâmetros Curriculares Nacionais, Orientações Curriculares Estaduais para o Ensino Médio e Princípios e Eixos da Educação na Bahia" (BAHIA, 2018, p. 4).

Fundamentados na teoria de Basil Bernstein sobre a estruturação do discurso pedagógico, Alferes e Mainardes (2018, p. 423) discutem os movimentos porque passam as políticas educacionais nos níveis macro, meso e micro. Nessa dimensão, é possível considerar o PPP do EMITec como um discurso pedagógico oficial, constituído no nível meso, "onde um texto (no caso, o texto da política) atravessa a sua primeira transformação", resultante de um conjunto de relações que se estabelecem entre vários campos envolvidos na sua geração, recontextualização e reprodução.

A propósito disso, os documentos oficiais nacionais citados, firmados no nível macro, "contexto no qual as políticas são feitas e produzidas", fazem parte do contexto de influência, proposto por Ball, Maguire e Braun (2016), sob o qual o PPP, que constitui o campo recontextualizador oficial do EMITec, foi escrito, transformando-se no discurso pedagógico 
oficial. Esse discurso, ao chegar nas telessalas do EMITec, nível micro, "onde o texto é transformado em prática escolar" também está sujeito a recontextualizações (ALFERES; MAINARDES, 2018, p. 423).

O PPP de uma escola ou, no nosso caso, do programa EMITec, equivale a um planejamento sistemático, servindo como referência às ações de todos os envolvidos no contexto escolar. Em tese, conforme aponta Veiga (2006, p. 17), ele “[...] exige dos educadores, funcionários, alunos e pais a definição clara do tipo de escola que intentam, requer a definição de fins". Portanto, a construção coletiva do PPP pode ser vista como uma forma de ultrapassagem das ligações hierárquicas e autoritárias rumo ao protagonismo.

A análise do PPP do EMITec não revela características de um projeto pautado na autonomia, uma vez que se trata de um documento padronizado, que, na prática, não contempla aspectos regionais e não apresenta um desenho curricular diferente do exibido nos documentos do Ensino Médio regular, o que nos induz a pensar que ele reflete os princípios dominantes de uma sociedade, que são gerados no campo do Estado sob a influência do campo internacional. Ball (2016) adverte que, tendo em vista que os sujeitos se tornam autores das políticas ao participar dos processos de tradução e recriação, para fazer uma análise ponderada de políticas educacionais, é necessário, do ponto de vista crítico, observar as várias nuances que elas apresentam.

A parte introdutória do PPP revela que as justificativas para a criação e implantação do EMITec estão baseadas nas necessidades advindas de outras políticas anteriores, principalmente na Lei de Diretrizes e Bases da Educação - LDB no 9.394 de 1996 (BRASIL, 1996), no tocante ao compromisso de alargar a assistência, garantindo a democratização do acesso a uma educação pública gratuita e inclusiva, apresentando "uma proposta didáticopedagógica inovadora para solucionar problemas educacionais para um Estado de grande territorialidade e desigualdades sociais" (BAHIA, 2018, p. 7). Essa questão também pode ser contatada em um dos objetivos do programa.

Assegurar a jovens e adultos que moram em localidades de difícil acesso, o acesso, a permanência e a conclusão da educação básica, por meio da intermediação tecnológica, possibilitando-lhes dar continuidade aos estudos em outro nível de ensino, além de favorecer o desenvolvimento pessoal e da cidadania (BAHIA, 2018, p. 9).

O documento analisado indica uma busca pela inclusão social. Simultaneamente, relacionamos essa ocorrência à tendência brasileira de articular reformas internas da educação com as reformas internacionais (CIAVATTA; RAMOS, 2012). De fato, a pobreza é o substrato 
necessário que os organismos internacionais utilizam para lançar mão de um discurso ideológico de combate às desigualdades. "As políticas educacionais voltadas à educação de adolescentes, de jovens e de adultos, fazem parte do grande campo das políticas sociais brasileiras, as quais, desde 1957, estão articuladas às políticas internacionais" (RIBEIRO, 2017, p. 171).

Ao descrever a posição dos sujeitos na divisão social do trabalho, Bernstein (1996, p. 155) afirma que "a condição mais primitiva para a localização das orientações de código é dada pela localização dos agentes na divisão social do trabalho de produção". Assim, a posição ocupada pelo indivíduo implica em uma comunicação mais ou menos elaborada, o que pode interferir no seu sucesso ou fracasso escolar. Para além do contexto familiar, se analisarmos o contexto da prática, seguindo a ótica de Bernstein, percebemos que ela utiliza significados universalistas, recebidos do contexto simbólico da classe média, sujeita a influências do mundo globalizado, uma vez que "a educação é um assunto de políticas regional e global e cada vez mais um assunto de comércio internacional” (BALL, 2004, p. 1108). Dessa forma, a escola se transforma em um sistema simbólico, sem ligação com as experiências familiares, o que pode levar ao fracasso escolar (BERNSTEIN, 1996; 1998).

O DPO que constitui o texto do PPP do EMITec ainda menciona, na sua argumentação em favor da implantação do EMITec, o compromisso com outras políticas nacionais em curso, dentre elas, o Plano Nacional de Educação (PNE), "Para viabilizar a continuidade dos estudos e sua consequente conclusão da educação básica de um quantitativo adequado de alunos" (BAHIA, 2018, p. 7), o que reforça a ideia anterior de internacionalização da educação, pois de acordo com Piccinini e Tonácio (2017, p. 61), o PNE faz "parte de um projeto amplo de políticas sociais, implantado na América Latina pelas frações burguesas dominantes que se referenciaram nas orientações de organismos financeiros internacionais", que, por sua vez, têm como premissa uma lógica empresarial que condiciona os seus investimentos em educação.

\section{Considerações finais}

Nossa análise sobre a estrutura e organização curricular do EMITec, presente no PPP, revela traços de um discurso influenciado pelas demandas do Estado, da economia e do campo internacional, o que extravia o EMITec do seu papel singular de destaque no desenvolvimento social e cultural.

A recontextualização também pode ser vista na transformação do discurso oficial durante o percurso em que ele é deslocado entre as duas instâncias de recontextualização até 
atingir o contexto das telessalas, fazendo com que o discurso reproduzido não corresponda exatamente ao discurso que foi produzido no CRO. Em relação aos critérios de avaliação, há um alto nível de recontextualização do que é proposto no CRO (PPP do EMITec), até ser colocado em prática pelo docente especialista, durante as teleaulas. Alguns instrumentos avaliativos seguem uma dinâmica que indica abertura para o protagonismo docente, flexibilizando a eles a promoção de algumas modificações.

\section{REFERÊNCIAS}

ALFERES, M. A.; MAINARDES, J. A recontextualização do Pacto Nacional pela Alfabetização na idade certa - PNAIC: uma análise dos contextos macro, meso e micro. Currículo Sem Fronteiras, v. 18, n. 2, p. 1-28, maio/ago. 2018.

\section{BAHIA (Estado). Projeto Político Pedagógico do Ensino Médio com Intermediação Tecnológica do Estado da Bahia - EMITec. Salvador: Secretaria de Educação, 2018.}

BAHIA (Estado). Secretária da Educação do Estado da Bahia. Portaria nº 424/2011. Implanta em Unidades Escolares da Rede Pública Estadual de Ensino o Programa de Ensino Médio com Intermediação Tecnológica. Diário Oficial, Salvador, 22 e 23 jan. 2011.

BERNSTEIN, B. A estruturação do discurso pedagógico: classe, códigos e controle. Trad. Tomaz Tadeu da Silva e Luís Fernando Gonçalves Pereira. Petrópolis: Vozes, 1996.

BALL, S. J. Vozes/Redes Políticas e um currículo neoliberal global. In: PEREIRA, M. Z. C. et al. Diferenças nas Políticas de Currículo. João Pessoa: UFPB, 2010.

BALL, S. J. Educação Global SA: novas redes políticas e o imaginário neoliberal. Trad. Janete Bridon. Ponta Grossa: UEPG, 2014.

BALL, S. J.; MAGUIRE, M.; BRAUN, A. Como as escolas fazem as políticas: atuação em escolas secundárias. Trad. Janete Bridon. Ponta Grossa: Editora UEPG, 2016.

BERNSTEIN, B. Pedagogía, control simbólico e identidad. Madrid: Morata, 1998.

BERNSTEIN, B. Das pedagogias aos conhecimentos. Revista Educação, Sociedade e Culturas, v. 1, n. 15, p. 9-17, 2001.

BERNSTEIN, B. A pedagogização do conhecimento: estudos sobre recontextualização. Cadernos de Pesquisa, São Paulo, n. 120, p. 75-110, nov. 2003.

BRASIL. Lei n. 9.394, de 20 de dezembro de 1996. Estabelece as diretrizes e bases da educação nacional. Brasília, DF, 23 dez. 1996. Disponível em:

https://www2.camara.leg.br/legin/fed/lei/1996/lei-9394-20-dezembro-1996-362578publicacaooriginal-1pl.html\#: :text=Estabelece $\% 20$ as $\% 20$ diretrizes $\% 20 \mathrm{e} \% 20 \mathrm{bases} \% 20 \mathrm{da} \% 20 \mathrm{educa} \% \mathrm{C} 3 \% \mathrm{~A} 7 \% \mathrm{C}$ 
3\%A3o\%20nacional.\&text $=\% \mathrm{C} 2 \% \mathrm{~A} 7 \% 201 \% \mathrm{C} 2 \% \mathrm{BA} \% 20 \mathrm{Esta} \% 20 \mathrm{Lei} \% 20$ disciplina,trabalh o\%20e\%20a\%20pr\%C3\%A1tica\%20social. Acesso em: 10 out. 2019.

CIAVATTA, M.; RAMOS, M. A "era das diretrizes": a disputa pelo projeto de educação dos mais pobres. Revista Brasileira de Educação, Rio de Janeiro, v. 17, n. 49, p. 11-37, abr. 2012.

FILHO, O. B.; SANTOS, L. M. dos. Ensino médio com intermediação tecnológica (EMITec): inclusão e escolarização na zona rural e regiões remotas. In: SANTOS, L. M. (Org.).

Educação Básica com Intermediação Tecnológica: tendências e práticas. Salvador: Fast Design, 2015. v.3. p. 19-33.

KRAWCZYK, N; SILVA, C. J. Desigualdades educacionais no ensino médio brasileiro: uma análise do perfil socioeconómico de jovens que realizaram o Exame Nacional do Ensino Médio. Sensos-e: revista multimédia de investigação em educação, v. 4, p. 12-23, 2017.

MAINARDES, J. Abordagem do ciclo de políticas: uma contribuição para a análise de Políticas educacionais. Educação e Sociedade, Campinas, v. 27, n. 94, p. 47-69, jan./abr. 2006.

MAINARDES, J.; STREMEL. S. A teoria de Basil Bernstein e algumas de suas contribuições para as pesquisas sobre políticas educacionais e curriculares. Teias, Rio de Janeiro, v. 11. n. 22. p. 31-54, 2010.

NEVES, I. P. et al. Os discursos instrucional e regulador em programas de ciências: estudo comparativo de duas reformas. Revista Portuguesa de Educação, Braga, v. 13, n. 1, p. 209$245,2000$.

OLIVEIRA, C. S. et al. O CEMIT e sua efetividade no acompanhamento pedagógico. In: SANTOS, L. M. (Org.). Educação Básica com Intermediação Tecnológica: tendências e práticas. Salvador: Fast Design, 2015. v. 3. p. 35-48.

PICCININI, C. L.; TONÁCIO, G. M. Valorização dos Professores no Plano Nacional de Educação (2014-2024): muito a ser feito pela valorização dos(as) profissionais de educação. In: EVANGELISTA, O.; SEKI, A. K. (Org.). Formação de professores no Brasil: leituras a contrapelo. Araraquara: Junqueira \& Marin, 2017. cap. 2, p. 59-84.

RIBEIRO, L. L. Formação inicial do professor para a EJA. In: EVANGELISTA, O.; SEKI, A. K. (Org.). Formação de professores no Brasil: leituras a contrapelo. Araraquara: Junqueira \& Marin, 2017. cap. 6, p. 169-196.

SANTOS, L. M. (Org.). Educação Básica com Intermediação Tecnológica: tendências e práticas. Salvador: Fast Design, 2015. v. 3.

SANTOS, L. M. dos et al. Sistema de Avaliação do Programa Ensino Médio com Intermediação Tecnológica (EMITec): possibilidades efetivas na construção do conhecimento. In: CONGRESSO ABED, 10., 2012. Anais [...]. 2012. Disponível em: http://www.abed.org.br/congresso2012/anais/207c.pdf. Acesso em: 3 maio 2019. 
SHIROMA. E. O et al. A tragédia docente e suas faces. In: EVANGELISTA, O.; SEKI, A. K. (Org.). Formação de professores no Brasil: leituras a contrapelo. Araraquara, São Paulo: Junqueira\&Marin, 2017. cap. 1, p. 17-58.

VEIGA, I. P. A. Perspectivas para reflexão em torno do Projeto Político Pedagógico. In: VEIGA, I. P. A. (Org.) Escola: espaço do projeto político pedagógico. 10. ed. Campinas: Papirus, 2006.

\section{Como referenciar este artigo}

CARNEIRO, E. F.; EUGENIO, B. G. Ensino Médio com Intermediação Tecnológica (EMITec): análise da proposta curricular. Revista on line de Política e Gestão Educacional, Araraquara, v. 25, n. 1, p. 205-222, jan./abr. 2021. e-ISSN:1519-9029. DOI: https://doi.org/10.22633/rpge.v25i1.13935

Submetido em: 16/05/2020

Revisões requeridas em: 23/07/2020

Aceito em: 28/11/2020

Publicado em: 02/01/2021 
